\title{
Las piedras del Zodiaco en el Lapidario de Alfonso $X$ el Sabio. Una selección para "ver con los ojos cerrados"
}

\author{
The Zodiac stones in the Lapidary of Alfonso $X$ "EI \\ Sabio". A selection to "see with closed eyes"
}

\author{
Victoria López-Acevedo, Javier Goñi y Juan C. Chicote \\ Departamento de Cristalografia y Mineralogía. Facultad de Ciencias Geológicas. \\ Universidad Complutense de Madrid, \\ José Antonio Nováis, 12. \\ 28040 Madrid. España \\ vcornejo@geo.ucm.es; correo_javi@hotmail.com; jcchicote@yahoo.es
}

Recibido: 2 de octubre de 2017.Aceptado: 2 de marzo de 2018. Publicado en formato electrónico: 6 de septiembre de 2018.

Palabras clave: Lapidario. Alfonso X “el Sabio”. Astrología. Zodiaco. Háptico. Mineral.

KeY WORDS: Lapidary.Alfonso X “El Sabio”.Astrology. Zodiac. Haptic. Mineral.

RESUMEN

En este trabajo se describe una colección de piedras del Zodiaco, que fueron citadas en el lapidario de Alfonso X el Sabio (s. XIII) y que han sido seleccionadas por tener unas propiedades especialmente adecuadas para ser reconocidas por el canal háptico'. Conociendo estas propiedades se podrá reconocer la piedra representativa de cada signo mediante esta vía de percepción. Partiendo de esta idea se ha desarrollado una actividad de carácter lúdico-científico que podría ampliar los recursos de personas con ceguera o discapacidad visual ya que supone una nueva vía de experimentación háptica, contribuye a mejorar el conocimiento del mundo mineral y es una aproximación a temas tan sugerentes como la astrología y la magia que encierran las piedras del Zodiaco.

\section{AbstRACT}

This paper describes a collection of Zodiac stones mentioned in the Lapidary of Alfonso $X$ "El Sabio" (XIII Century). They have been selected because their attributes make them specially suitable to be recognised through the haptic channel. The knowledge of this attibutes enables the haptic recognition of the Zodiac sign's representative stone. On this basis, an activity that unites leisure and science has been developed, hoping it will help to expand the resources for blind or visually impaired people, as it explores a new level of haptic experience while it contributes to enhancing the knowledge of the mineral world and serves as an approach to highly suggestive themes such as Astrology and the magic of the Zodiac stones.

Descriptions are based on the scientific comments by Professor José Luis Amorós to the first Lapidary of Alfonso X "El Sabio" (Alfonso X, I 982 Vol. II), kept in the Real Biblioteca del Monasterio de San Lorenzo de El Escorial. The tactile scrutiny needed to identify the depicted properties is focused on the recognition of shape, feel, hardness, density and some others such as magnetism, static electricity, etc. (CHICOTE et al., 20I5). Finally, the different legends, myths and beliefs mentioned have been included in their most spread versión. They have been drawn from the Lapidary itself or similar sources. Though most of them lack a scientific basis, it is important to keep in mind that they are part of the astrological knowledge of the momento.

\section{INTRODUCCIÓN}

"Todas las cosas que están bajo los cielos se mueven y se enderezan por el movimiento de los cuerpos celestiales". Esta frase de Aristóteles que inicia el prólogo de I. Se refiere al conjunto de sensaciones no visuales y no auditivas que experimenta un individuo. 
El Lapidario de Alfonso X el Sabio, resume el pensamiento reinante durante siglos de que los astros determinan todos los acontecimientos terrenales, sean éstos del tipo que sean. Este pensamiento se plasmó durante la Baja Edad Media en unos textos denominados lapidarios. En ellos, se describen las propiedades mágicas y curativas de las piedras (minerales y fósiles) y su relación con los planetas, las estrellas y otros cuerpos celestes.

Alfonso X de Castilla (I22I-I 284) fue hijo de Fernando III «el Santo» y de la noble alemana Beatriz de Suabia. Desde muy joven participó activamente en los asuntos de estado y en importantes operaciones militares. Sin embargo, a pesar de sus éxitos como político y hombre de estado, se le conoce sobre todo por su faceta como intelectual y científico que le valió el sobrenombre de "el Sabio". Rodeado de una serie de estudiosos latinos, hebreos e islámicos que formaban parte de la conocida como Escuela de Traductores de Toledo, este rey patrocinó, supervisó e incluso participó con su propia escritura en numerosas traducciones y obras literarias y de investigación científica. Una de sus obras más conocidas fue el Lapidario que se acabó de traducir en Toledo en 1250.

En realidad, esta obra consta de cuatro lapidarios. El primero y más extenso se refiere a las piedras clasificadas según los signos del Zodiaco. Desde el punto de vista astrológico, el Zodiaco es una franja celeste en la que se observa, desde la tierra, el movimiento de los planetas del sistema solar, la Luna y, por supuesto, el Sol. Esta franja circular, de 360 grados, rodea a la Tierra como un anillo que se sitúa algo inclinado con respecto a la línea del ecuador. Se divide en doce arcos de 30 grados que se llaman signos zodiacales. Estos arcos incluyen, cada uno, la constelación tradicional a la que deben su nombre. Dado que la mayoría de las constelaciones tienen nombres de animales se ha llamado Zodiaco a esta franja (del griego "zodiakós"; "zoo", animal y “diakós”, camino).

El primer lapidario contiene la descripción de 301 piedras (la mayoría minerales y también rocas o fósiles) y otros elementos (plantas y huesos o caparazones de animales) distribuidos en doce capítulos correspondientes a los doce signos (ALFONSO X, 1982, Vol. I). En cada signo se deberían describir 30 de estos elementos, uno por cada grado del signo. Sin embargo hay tres que aparecen incompletos: Leo, Acuario y Piscis, donde faltan 29, 2 y 28 elementos, respectivamente. Es posible que el copista no incluyera esta información o que las hojas se perdieran antes de ser encuadernado el libro. No obstante, en seis casos ha sido posible recuperar el nombre de la piedra perdida, ya que el segundo lapidario hace referencia a estas piedras indicando el grado que ocupaban en el primero. Así se recupera el nombre, aunque no la descripción ya que solo el primer lapidario describe (LAPIDARIO, s.f.). Estas descripciones comprenden el nombre en varios idiomas, la naturaleza de la piedra o del elemento en cuestión, el lugar donde se encuentra, sus propiedades mágicas y médicas (o lo que llaman "virtud") y la estrella o estrellas que corresponden a su grado y de las que reciben esa "virtud" (ALFONSO X, 1982 Vol. II).

En el presente trabajo se han seleccionado doce piedras, una por cada signo del Zodiaco. La selección se ha realizado entre las 209 piedras y otros elementos del lapidario que han podido ser identificados de acuerdo con los conocimientos actuales (los 92 ejemplares restantes no son reconocibles, AmORós, I96I). En la Tabla I se indica el nombre de estos elementos que a menudo aparecen repetidos en varios signos diferentes. Cada una de las piedras elegidas posee propiedades exclusivas y reconocibles a través del tacto (se ha evitado expresamente incluir piedras con características comunes que puedan confundirse entre sí). De esta forma, conociendo las propiedades de la piedra que se asocia a un signo concreto se podría diferenciar entre todas las demás mediante esta vía de percepción. Con esta actividad de carácter lúdico-científico se pretenden ampliar los recursos de personas con ceguera o discapacidad visual; constituye un campo diferente de experimentación háptica, contribuye a mejorar el conocimiento del medio natural (mundo mineral en este caso) y abre las puertas a un nuevo entretenimiento asociado a temas tan populares y conocidos como los horóscopos, las predicciones astrológicas y las piedras del Zodiaco.

\section{DESCRIPCIÓN DE LAS “PIEDRAS” SELECCIONADAS}

A continuación se describen estas piedras de acuerdo con el mismo esquema seguido en el lapidario: signo del Zodiaco al que se asocian, su simbología y período del año solar correspondiente; nombre de la piedra tal como aparece en el lapidario y denominación actual; descripción de las propiedades que nos van a permitir reconocerlas por el canal háptico (su naturaleza) y finalmente sus otras propiedades, mágicas 
Tabla I. "Piedras" (minerales, rocas, fósiles, plantas y esqueletos de animales) identificadas por Amorós en el primer Lapidario de Alfonso X “El Sabio” (AlfONso X, I 982 Vol. II) de acuerdo con criterios actuales.

ARIES Arcillas verdes y otras (no identificadas). Azabache // Calcedonia estalactítica. Caliza. Caolín azul (teñido de sulfato de cobre). Carneola amarillenta. Corindón // Jaspe hialino. Jaspe veteado blanco // Lava. Limonita pseudomórfica de pirita (forma de cubo) // Magnetita // Obsidiana. Ópalo noble // Pedernal (variedad de jaspe de color ahumado). Perla. Piedra de toque de los orfebres (no se asocia a ningún mineral o roca concreto. Lo importante es su color negro y que no sea atacada por los ácidos). "Piedra del águila" (nódulo hueco de limonita u óxido de manganeso que lleva en su interior uno o varios núcleos arcillosos que suenan al agitarlos). Piedra pómez. Pisolitos de manganeso // Salitre puro (eflorescencias). Salitre mezclado con arcilla. Salmiak (sal de amoniaco) //Wolframita.

TAURO Adularia o piedra de Luna.Alabastro. Asbesto // Cálculos humanos. Coral negro. Coral rojo. Corindón. Crisoprasa. Cuarzo rosa // Diamante // Esmeralda. Esmeril (granos de corindón, magnetita, oligisto y cuarzo). Esponja // Hierro // Magnesita. Malaquita con limonita. Marcasita. Mármol // Piedra córnea (variedad de jaspe). Pirita esferulítica // Rutilo // Sepiolita. Siderita. Siderita con azurita // Topacio. Turmalina o corindones nobles (de colores variados). Turmalina verde.

GémINIS Ágata con inclusiones de pirolusita.Alejandrita (variedad de crisoberilo).Arcilla roja (no identificada) // Baritina // Caliza. Caolín // Fosforita // Granate // Heliodoro (berilo dorado). Hematites botroidal // Lazulita // Malaquita con algo de pirita. Mármol // Oro. Oropimente. Óxidos de hierro // "Piedra de la serpiente" (zafiro o rubi). Piedras bezoares. Púas de centollo // Siderita con malaquita. Sulfatos de hierro // Talco.

CÁNCER Alabastro. Arcilla verde (no identificada). Azurita, malaquita y óxidos de hierro // Caliza terrosa. Caolín verde (impregnado de malaquita). Cerusita. Cobre abigarrado (calcosina y bornita). Concha de balanus // Dendritas de pirolusita sobre pizarra o caliza // Galena. Gallipavo (piedras que se encuentran en la molleja de las gallináceas). Glauberita y mirabilita. Grafito // Limonita o siderita // Magnesita. Malaquita. Mercurio. Molibdenita o esmaltina // Ocre rojo (oligisto). Óxidos y carbonatos de hierro // "Piedra judaica" (¿espículas de erizo fósiles?). Plata técnica (obtenida por un proceso metalúrgico a partir de minerales de plomo argentífero). Plomo técnico (plomo o estaño obtenido por un proceso metalúrgico) // Sepiolita // Topacio o zircón //Verdet (acetatos y carbonatos de cobre pulverulentos) // Wolframita // Yeso selenita (o especular).

$\begin{array}{ll}\text { Azufre. } & \text { Jacinto rojo, rubí y topacio (según el segundo lapidario). }\end{array}$

VIRGO Ámbar // Boratos naturales (bórax, boracita, pandermita) // Calcantita. Cantos rodados de cuarzo. Caparrosa (minerales oxidados de cobre y hierro). Cobre o plata nativos con forma dendrítica // Granate // Hematites // Mármol. Molibdenita // Piedra pómez. Pirita limonitizada. Plomo // Sales (eflorescencias de origen lacustre. Sin identificar). Serpentina con fibras de crisotilo // Travertinos lacustres.

LIBRA Algas marinas (diferentes tipos). Arcilla arenosa azul (sin identificar). Arena de mar. Asfalto natural // Calcopirita ("marcasita cobreña") // Esponja de mar. Esteatita // Fósiles // Granate. Granate verde (variedad uvarovita) // Limonita // Mica dorada. Mispiquel ("marcasita argéntea") // Otolitos que se encuentran en la cabeza de los peces (posibles anguilas) // Pez fósil. Pirita ("marcasita aurea") // Siderita con malaquita.

EsCORPIO Aragonito coraloide. Arena encontrada en la cavidad gástrica de algunos peces (holoturias). Azurita o lazulita // Basalto columnar o berilo verde // Calamina. Cantos rodados de cuarzo lechoso. Carnalita con arcilla. Casiterita "rubia”. Cristal de roca (variedad de cuarzo) // Depósitos calcáreos de laguna. Dicroita (antigua denominación de la cordierita) // Esmeralda u Olivino. Estibina o jamesonita // Fluorita // Galena masiva. Geoda // Incienso // Limonita nodular. Limonita seudomórfica de pirita // Mucílago que recubre las piedras // Obsidiana. Ocre amarillo. Oropimente // Pirolusita // Querargirita // Siderita seudomórfica de calcita // Testuz del carnero.

SAGITARIO Alumbre. Amatista. Arena de cuarzo (de la que se utiliza para fabricar el vidrio). Asfalto natural // Baritina. Boracita // Cálculo biliar. Cardenillo de cobre. Cobre técnico (obtenido por un proceso metalúrgico). Costras de carbonato cálcico formadas en los calderos. Crisocola // Distena // Geoda // Masicote. Mica (lepidocrocita o biotita) // Natrón. Nitro // Oropimente // Pirargirita (plata roja oscura o rosicler oscuro). Pirolusita. Proustita (plata roja clara o rosicler claro) // Rejalgar // Sal común con impurezas de arcilla o de carnalita. Sal gema. Siderita. Sulfuros y carbonatos cálcicos depositados en manantiales de aguas termales y sulfurosas // Ulexita.

CAPRICORNIO Alejandrita. Arcilla roja expansiva (sin identificar). Azabache o pizarra negra. Azurita // Bronce // Cantos rodados de cuarzo. "Clinia" (residuos de un horno de fundición de cobre). Cornalina. Creta verde // Hidrocincita (calamina blanca) // Lava. Litargirio rojo // Melanterita. Moscovita pulverulenta // Piedra esmeril. Piedra judaica (iespículas de erizo fósiles?) // Smithsonita // Teruelita //Witherita o cerusita // Xilópalo // Yeso.

AcuArio Arcilla con óxidos metálicos negros (sin identificar). Arenisca sin consolidar // Bauxita. Bornita. Brochantita // Caparazón de cangrejo marino. Cinabrio. Cuarzo lechoso // Dendritas de pirolusita sobre siderita o caliza // Eje central de la concha del caracol marino // Falsas amatistas (ise refiere a fluoritas o vidrio o... de color violeta?). Fluorita // Glauconita. Goethita y otros óxidos de hierro // Hematites roja concrecionada // Jaspe // Limonita con malaquita // Mica dorada // Piedra bezoar (encontrada en el aparato gástrico de la liebre). Piedra con corindón. "Piedrecillas" que se encuentran en las esponjas. Pseudomalaquita.

PIscIs Baritina // Granate piropo o espinela roja. Azabache, jacinto y turquesa (según el segundo lapidario) 
y terapéuticas (su virtud). Las descripciones se basan en los comentarios científicos del profesor José Luis Amorós al primer lapidario de Alfonso X el Sabio (Alfonso X, 1982 Vol. II), conservado en la Real Biblioteca del Monasterio de San Lorenzo de El Escorial y en un trabajo previo del mismo autor (AMORós, 196I).

Las acciones de escrutinio táctil necesarias para identificar las propiedades descritas se centran en el reconocimiento de la forma (irregular, cristalina...), tacto (frío, cálido, suave...), dureza (se raya con la uña, difícil de rayar...), densidad (relación pesotamaño) y otras muy diversas como el carácter magnético, electricidad estática, exfoliación, fractura, etc. (CHICOTE et al., 20I5).

El trabajo incluye, además de la Tabla I en que se muestran todas las piedras del Lapidario que han podido ser identificadas de acuerdo con los criterios actuales, otras dos tablas (II y III). En la Tabla II se resumen las propiedades que permiten el reconocimiento de todas las piedras seleccionadas a través del canal háptico, indicando también sus usos más comunes. Mientras que en la Tabla III se especifican propiedades como la composición química, sistema cristalino y otros datos de carácter formal que aunque no siempre van a ser aprehensibles por el tacto, complementan y amplían la utilidad y el rigor de este trabajo.También se incluyen dos láminas en las que se muestran imágenes de las variedades minerales elegidas para cada signo junto con su descripción textual que posibilita la información visual presentada a personas ciegas o con baja visión.

Por último, de las diferentes leyendas, mitos y creencias relatadas en el trabajo se han incluido las versiones más extendidas y aceptadas. Se han extraído del propio lapidario o de fuentes similares. Aunque la mayoría de ellas carecen de una base científica, es importante que sean entendidas en su justa medida, como parte del saber astrológico que en aquella época estaba considerado como la fuente de todo conocimiento.

Aries

Del 21 de marzo al 20 de abril. Es el primer signo zodiacal. Entre otras representaciones se le ha atribuido la del carnero alado, Crisómalo, cuya lana era de oro. La piel de este carnero era el vellocino de oro que aparece en la historia de Jasón y los argonautas. Se suele simbolizar como un carnero con la cabeza vuelta hacia atrás, contemplando sus mechones dorados.

La piedra seleccionada es magnetat, magnetes o aimant, actualmente conocida como magnetita, que corresponde al grado uno del signo. Se trata de un compuesto de hierro que puede formar cristales bien desarrollados, generalmente octaedros ${ }^{2}$, o presentarse masivo. Se reconoce sobre todo porque es fuertemente atraída por los imanes $^{3}$. También ayuda a la identificación su alta densidad. Tablas II y III; Lámina I, figura I.

Hay también ejemplares de magnetita que se comportan como imanes naturales capaces de atraer limaduras de hierro e incluso de orientarse si se les suspende de un hilo, de modo que sus extremos apuntan a los polos norte y sur del campo terrestre. A estos ejemplares se les denomina piedra imán y fueron los primeros materiales utilizados en la construcción de brújulas. Un dato curioso es la presencia de cristales de magnetita en el organismo de ciertas bacterias ${ }^{4}$ y en el cerebro de algunas especies de aves migratorias, como las conocidas palomas mensajeras ${ }^{5}$. Se piensa que la presencia de estos cristales les permite orientarse en el campo magnético terrestre (OYARZúN, 20I5).

El Lapidario dice de ella que tiene la virtud de conferir valor, fuerza y altivez a la persona que la lleva. Además, se creía útil como antídoto y revulsivo, para la curación de llagas y heridas causadas por hierros emponzoñados y para facilitar la expulsión de veneno ingerido.

Tauro

Del $2 \mid$ de abril al $2 \mid$ de mayo. Este es el segundo signo zodiacal y simboliza, según algunas opiniones, al toro blanco en que se transformó Zeus para raptar y llevarse a

2. Figura geométrica de ocho caras idénticas que tienen forma de triángulo equilátero. Podría describirse como dos pirámides de cuatro caras unidas por la base. Es uno de los cinco sólidos platónicos.

3. Esta propiedad se conoce como ferromagnetismo.

4. Magnetospirillum Gry physwaldense.

5. Columba livia domestica. 
Tabla II. Propiedades de la selección reconocibles por el canal háptico. Usos más comunes.

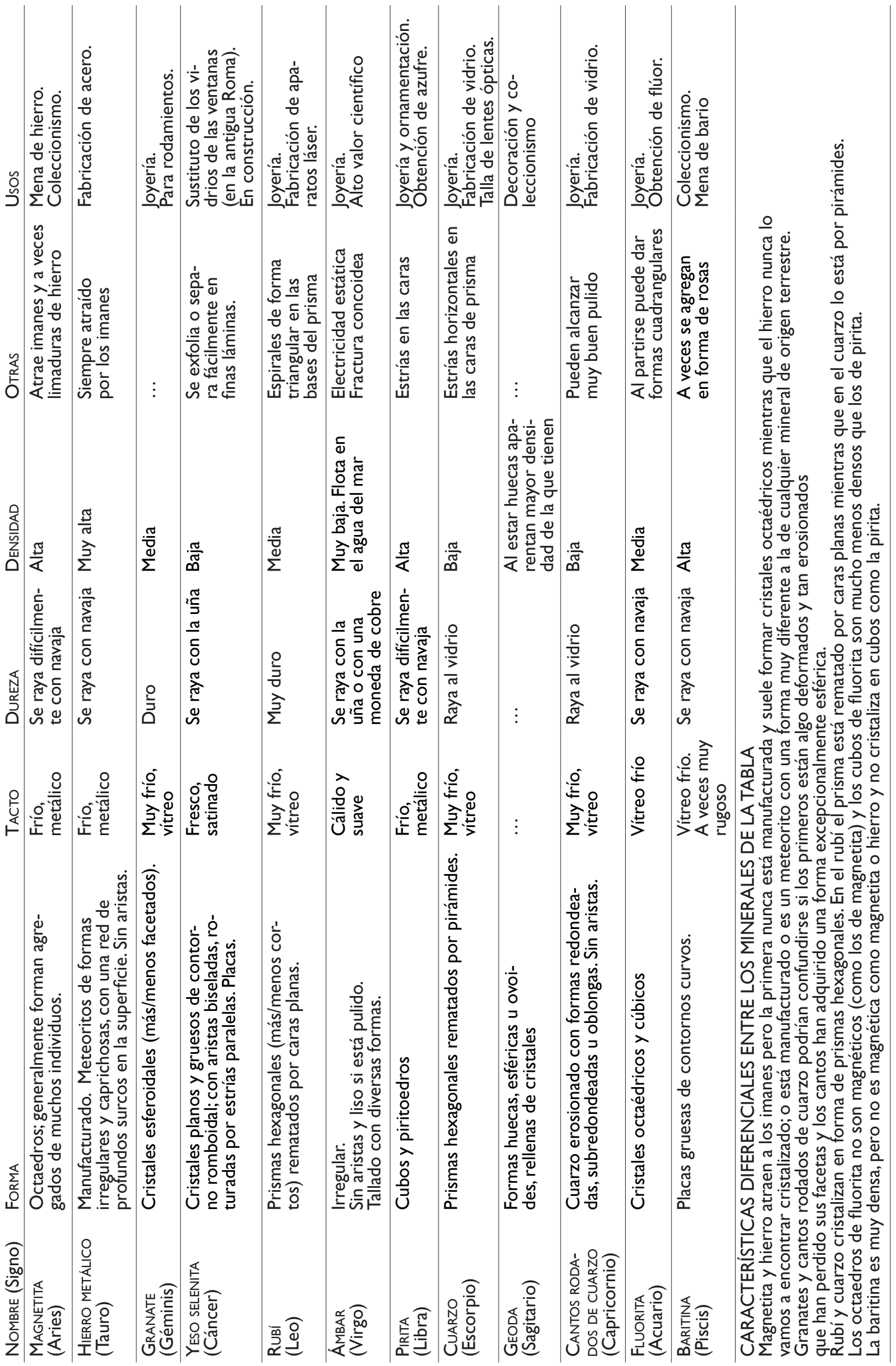


López-Acevedo,V., Goñi, J. \& Chicote, J. C.

Tabla III. Propiedades físicas y químicas de los minerales seleccionados para este trabajo.

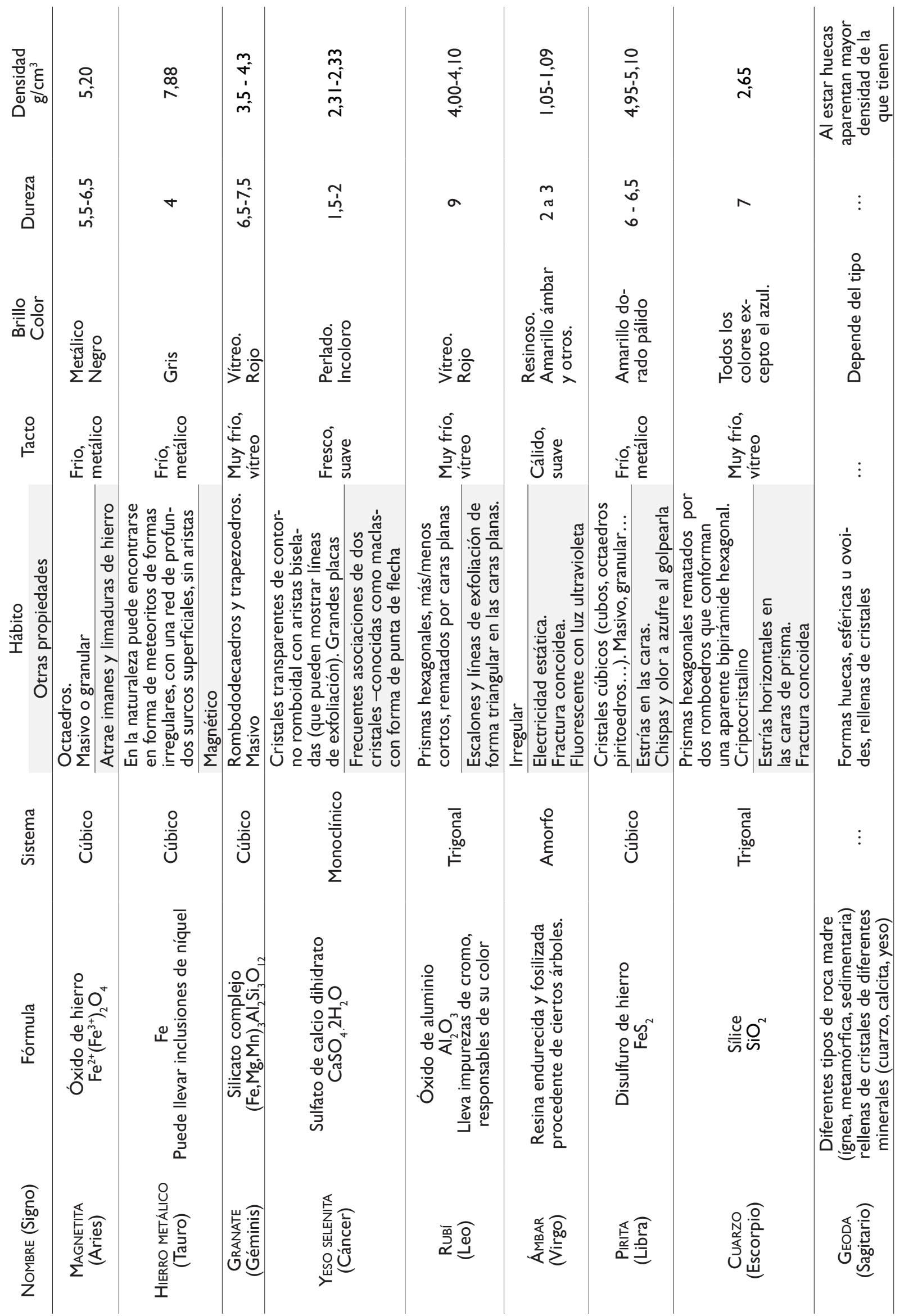


Europa a través del mar hasta la isla de Creta. Se representa con un toro lleno de fuerza y vigor.

La piedra seleccionada corresponde al grado veinticuatro del signo. Se trata del fierro, hierro actual. De él dice El Lapidario que "esta piedra es mineral, puesto que es metal y nace en muchas partes del mundo. Y cuando la quieren trabajar la meten al fuego y calentándola y luego la extienden como quieren. Es de las piedras más conocidas que el hombre emplea".

Este párrafo hace referencia al hierro pero una vez extraído del mineral ya que, aunque se trata de un componente mayoritario del núcleo de nuestro planeta, apenas se encuentra en estado puro en la superficie terrestre. Esto se debe a su gran inestabilidad frente a los procesos meteóricos naturales que lo alteran para dar diferentes minerales, sobre todo óxidos. Existe sin embargo otra fuente de hierro de origen natural aunque extraterrestre. Se trata de los meteoritos férricos que aunque pudieron formarse hace millones de años han estado preservados de la oxidación por el vacío del espacio, hasta su caída en la tierra.

En resumen, es un mineral que lo vamos a encontrar manufacturado, en forma de acero ${ }^{6}$, que constituye todo tipo de objetos, adornos, llaves, tijeras, etc., o en los meteoritos que tendrán la forma de un metal fundido, irregular, con relieves redondeados y suaves. El hierro siempre será atraído por un imán. Además es muy denso y con tacto metálico. Tablas II y III; Lámina I, figura 2.

Respecto a sus propiedades curativas se dice que el uso de las escorias molidas y las limaduras calentadas y mezcladas con agua 0 vino podían curar muchas enfermedades.

\section{Géminis}

Del 22 de mayo al 21 de junio. Géminis o los Gemelos es la tercera constelación zodiacal. Según la mitología podrían ser Cástor y Pólux, los hijos de Leda y de Zeus. Se representa mediante dos figuras humanas.

La piedra seleccionada es la piedra del sueño, que corresponde al grado octavo del signo. Se trata de una piedra preciosa, transparente, fuerte y dura que muestra resplandores como de fuego y que ha sido interpretada como granate. Los granates cristalizan con formas redondeadas y con facetas, como las cuentas de un collar (trapezoedros $^{7}$ o rombododecaedros ${ }^{8}$ ). Esto unido a su gran dureza, permite su uso directamente para ser engarzados en joyas y otros objetos decorativos sin necesidad de tallarlos. A menudo solo hace falta perforarlos y quizás rematar con un ligero pulido. También es característico su tacto vítreo y frío. Tablas II y III; Lámina I, figura 3.

Al parecer se creía que con solo llevarlas encima podían tener efectos adormecedores, analgésicos e incluso anestesiantes.

\section{Cáncer}

Del 22 de junio al 22 de julio. Cáncer, Cancro, el Cangrejo es el cuarto signo zodiacal. La mitología lo relaciona con el cangrejo gigante que fue enviado por la diosa Hera para atacar con sus pinzas a Hércules mientras este luchaba contra la monstruosa Hidra en las lagunas de Lerna. En respuesta, el héroe griego enfurecido lo aplastó

6. El acero es una aleación de hierro y carbono que mejora las propiedades físico-químicas del hierro. A principios del siglo $X X$ se inventó el acero inoxidable que lleva una pequeña cantidad de cromo. Este elemento le da un aspecto brillante y lo hace altamente resistente a la suciedad y a la oxidación.

7. Figura geométrica de veinticuatro caras con forma de trapezoide.

8. Figura geométrica de doce caras con forma de rombo. 
con su talón y continuó la batalla. Hera, sin embargo, recompensó su acción y lo convirtió en la constelación de Cáncer. Se representa con un cangrejo.

La piedra seleccionada es la que llaman scopetina de la luna que corresponde al grado dieciséis del signo y que ha sido interpretada como selenita. Este mineral que debe su nombre a Selene, diosa griega de la Luna, es una variedad de yeso que se encuentra en forma de cristales transparentes gruesos, con los bordes biselados y contorno romboidal, o también en masas cristalinas. En algunas localidades, constituyen extensas planchas que pueden dividirse en placas transparentes muy finas que se conocen como lapis especularis y que fueron muy valoradas en la Antigua Roma, donde las utilizaban en lugar de los vidrios de las ventanas, cuando aún no se habían aprendido a fabricar estos (GARCíA-Ruiz, 2008). Fue especialmente famoso el extraído en Hispania, en unas minas halladas en las proximidades de Segóbriga (Cuenca). Esta facilidad que tienen algunos minerales para dividirse en placas, que llegan a ser láminas muy finas, se conoce como exfoliación.

Se reconoce por su forma romboidal de aristas biseladas, en las que se observan estrías paralelas ${ }^{9}$ y porque es tan blando que se raya con la uña. Tablas II y III; Lámina I, figura 4.

De la virtud de esta piedra dice El Lapidario que "si dieren de la pulidura de ella a beber al que ha demonio, sana luego" lo cual podría referirse a la curación de personas poseídas o locas.

Leo

Del 23 de julio al 23 de agosto. Leo o el León es el quinto signo del Zodiaco. Se supone que hace referencia al León de Nemea, que fue muerto a manos de Hércules para cumplir con el primero de sus trabajos. El héroe lo estranguló ya que su piel era impenetrable. Posteriormente lo desolló, ayudándose de las propias garras del león, y consiguió su piel que desde entonces vistió a modo de armadura, usando su cabeza como yelmo. Se simboliza con un león.

Este es uno de los signos incompletos del primer lapidario en los que falta la descripción de varias piedras. En este caso, la única que figura es el azufre que resulta difícil de reconocer por el canal háptico exclusivamente. Hubo que acudir al segundo lapidario (Rodríguez M. Montalvo, I98I) para encontrar una piedra más adecuada a nuestros propósitos. La piedra seleccionada ha sido el rubí, que en el primer lapidario debía ocupar el grado trece del signo.

El rubí está considerado como una de las cuatro gemas preciosas, junto con zafiro, esmeralda y diamante. Rubí y zafiro son las dos variedades nobles del mineral corindón que se diferencian exclusivamente por el color. Se llaman rubíes a los corindones rojos y zafiros a todos los demás colores. De hecho el nombre de rubí viene de "ruber" que significa rojo en latín. El rubí cristaliza en forma de prismas hexagonales, más o menos cortos, rematados por caras planas y es el segundo mineral más duro después del diamante. En las caras planas que rematan el prisma se forman espirales de contorno triangular que llegan a ser muy pronunciadas y perceptibles al tacto.

Al ser tan duros resisten muy bien el desgaste por fricción. Esto los hace especialmente útiles en la fabricación de relojes, como rodamientos de las partes mecánicas que están en continuo movimiento, para evitar el roce entre las piezas. Otra aplicación muy importante de los rubíes es para la fabricación de aparatos láser ya que el rubí, debidamente estimulado, es capaz de producir el rayo láser ${ }^{10}$. Tablas II y III; Lámina I, figura 5 .

Aunque el segundo lapidario no describe la naturaleza de las piedras sí habla de sus poderes mágicos. En esta ocasión dice que "el que tuviere consigo esta piedra será ardid y de gran esfuerzo, y bien quisto de los reyes" que se podría interpretar como hábil, ingenioso, esforzado y querido de los reyes.

\section{Virgo}

Del 24 de agosto al 23 de septiembre. Es el sexto signo del Zodiaco. Se simboliza por una virgen que ha sido identificada con varias diosas. En la mitología griega representaba a Astrea, una titánide hija de Zeus y Temis. Fue la fiel aliada de Zeus durante la guerra de los Titanes y como recompensa por su lealtad este le permitió conservar su

9. Dichas estrías son la manifestación externa de los planos de exfoliación del yeso.

10. La palabra LÁSER es un acrónimo compuesto por las siglas: Light Amplified by Stimulated Emission of Radiation (Ampliación de la Luz por Emisión Estimulada de Radiación). 
virginidad (es la única virgen entre todas las Titánides) y le dio un lugar entre las estrellas como la constelación de Virgo. Se representa por una figura femenina.

La piedra seleccionada es el carabe que ha sido reconocida como ámbar. En El Lapidario se describe su propiedad más característica, la de atraer finas laminillas, hojas y pajas; también su olor a resina y su color dorado. Corresponde al grado veintinueve del signo.

El ámbar se forma por fosilización de la resina procedente de ciertos árboles". Este proceso que puede durar entre 2 y 10 millones de años da como resultado una piedra de gran belleza, blanda, muy ligera (flota en el agua del mar), de tacto cálido y suave, con fractura concoide y que cuando se frota es capaz de atraer pedacitos de papel y partículas similares; es lo que se conoce como electricidad estática' ${ }^{2}$. Tablas II y III; Lámina I, figura 6.

Uno de los principales usos del ámbar es en joyería y en la elaboración de objetos decorativos ${ }^{13}$. El ámbar tiene además un gran interés científico, ya que la resina original puede atrapar insectos, arañas, plantas, hongos, gusanos e incluso, vertebrados como lagartos o ranas. También se encuentran gotas de lluvia, polvo volcánico, pelos de mamíferos, plumas y seres biológicos microscópicos. Estas inclusiones han permitido avanzar en el conocimiento de la vida de hace cientos de millones de años. Es una ventana abierta al pasado que proporciona una información inestimable sobre la evolución y diversificación de vegetales y animales.

Se le atribuía la virtud de cortar la hemorragia nasal, impedir el vómito y sanar la coriza $^{14}$, el temblor de corazón y el dolor de estómago.

\section{Libra}

Del 24 de septiembre al 23 de octubre. Es el séptimo signo del Zodiaco. Podría hacer referencia a Dice, una de las Horas hija de Temis y Zeus, e incluso a la misma Astrea que también personificaba la justicia en el mundo de los hombres. Para velar por ella vivió en la tierra hasta que los humanos se corrompieron y empezaron las guerras y las enfermedades. Entonces Zeus la elevó al cielo, situándola junto a él en el Olimpo y la balanza que llevaba en las manos la convirtió en la constelación de Libra. Una balanza es el símbolo del signo.

La piedra seleccionada es la marcasita aurea que ha sido identificada como pirita y que pertenece al grado veintiuno del signo. El Lapidario describe su color de oro, las centellas que produce al golpearla y el azufre que lleva en su composición. La pirita tiene además otras propiedades inconfundibles como son: su elevada dureza, su tacto metálico y frío, su alta densidad y sobre todo las típicas formas del sistema cúbico que presenta cuando está bien cristalizada, cubos perfectos o pentagonododecaedros, también conocidos como piritoedros ${ }^{15}$. Estos cristales muestran a menudo estrías en las caras, a veces tan profundas que resultan perceptibles al tacto.

Una anécdota curiosa es que su color dorado ha llevado en ocasiones a que coleccionistas poco expertos la confundan con el oro, tanto es así que también se la conoce como "el oro de los tontos". Además de otras aplicaciones industriales, la pirita se ha utilizado para la fabricación de joyas y objetos decorativos. Un buen ejemplo es el trofeo Balón de Oro que se disputan las principales estrellas del futbol mundial y que está montado sobre una base de pirita. Tablas II y III; Lámina II, figura I.

En lo referente a sus virtudes dice que es buena para limpiar las llagas, sanar las fístulas de cualquier lugar que sean, y quitar la tela que se hace en los ojos. Además de quitarle el miedo al niño chico si se la cuelgan a modo de amuleto.

\section{Coniferas y algunas angiospermas.}

12. La palabra electricidad viene del griego electrum que es como se conocía al ámbar en la época homérica.

13. Fue famosa la cámara de ámbar del palacio de Catalina de Tsárskoye Seló en San Petersburgo. Una lujosa habitación del zar de Rusia decorada con paneles, zócalos y muebles formados por miles de piezas de ámbar. Fue saqueada por el gobierno del Tercer Reich y vista por última vez durante los últimos meses de la Segunda Guerra Mundial. En la actualidad existe una copia en el mismo palacio de Catalina donde estuvo inicialmente.

14. Rinitis aguda.

15. Cristal equidimensional formado por doce caras de forma pentagonal. Se asemeja mucho a uno de los cinco sólidos platónicos. 


\section{Escorpión}

Del 24 de octubre al 22 de noviembre. Escorpión o Escorpio es el octavo signo del Zodiaco. Aunque existen varias versiones acerca del significado de esta constelación, la más extendida es que representa al escorpión que mató al gigante Orión, bien por encargo de Gea, alarmada ante el anuncio del gigante cazador de que no iba a dejar vivo a ningún animal que estuviera sobre la faz de la tierra, o bien por encargo de Artemisa para defenderse de Orión que pretendía seducirla. Se representa con un escorpión.

La piedra seleccionada es el cristal que es el nombre clásico del cuarzo y corresponde al grado quinto del signo. Se creía que esta piedra era agua tan congelada que ya no podía fundir. Describe la variedad conocida como cristal de roca, dura y de color como agua. También explica que se funde con el fuego y que al fundirse puede adoptar el color y la forma que se quiera. Es decir, nos habla del procesado del vidrio. Además añade que si la figura obtenida es bien redonda y la ponen al sol concentra los rayos de este y es capaz de quemar materiales que arden fácilmente, como hacen las lentes convergentes.

El cuarzo es uno de los minerales más comunes en la corteza terrestre. Forma cristales de todos los tamaños; los hay tan pequeños que solo se pueden reconocer con el microscopio ${ }^{16}$ o también grandes y muy bien desarrollados, con forma de prismas de contorno hexagonal rematados por pirámides en sus extremos. Son frecuentes las estrías horizontales en las caras del prisma que a veces se pueden reconocer al rascarlas con la uña. Es muy duro, de tacto vítreo y muy frío. Se considera una gema muy apreciada para engarzar en joyas y objetos decorativos ya que además de su gran dureza presenta una amplísima gama de colores. Otros cuarzos se utilizan en la industria, los de gran calidad y transparencia para tallar lentes de aparatos de óptica y los más vulgares para la fabricación de vidrio. Tablas II y III; Lámina II, figura 2.

Existe una variedad conocida como diamante Herkimer ${ }^{17}$, que se considera el diamante de los cuarzos. Posee una transparencia extraordinaria, es un poco más duro que los otros cuarzos y tiene una forma tan perfecta que parece que ha sido tallado por manos delicadas y sabias. Además, su pequeño tamaño $(5-6 \mathrm{~cm})$ posibilita su uso en joyería directamente, sin necesidad de otro tipo de manipulación.

El Lapidario no describe los poderes sanadores ni mágicos de este mineral que, sin embargo, es uno de los más reconocidos y de mayor simbolismo en todos los ambientes esotéricos.

\section{Sagitario}

Del 23 de noviembre al 21 de diciembre. Es el noveno signo zodiacal. Según la leyenda simboliza al sabio centauro Quirón, que fue un gran educador en música, arte, caza, moral, medicina y cirugía, y tutor de muchos de los héroes más destacados en la mitología griega. Se representa mediante un centauro armado con un arco y a punto de disparar una saeta.

La piedra seleccionada es la piedra del fuego que corresponde al grado dieciséis del signo y que por la morfología descrita "De forma es de escudilla, de un cabo redonda, $y$ del otro como cavada" podría tratarse de una geoda, aunque el resto de características que cita hacen difícil asegurarlo con precisión.

El término "geoda" no se refiere a ningún mineral en concreto, sino a unas formaciones huecas, esféricas u ovoides, tapizadas interiormente por una capa de cristales perfectamente formados o dispuestos en concreciones. A primera vista parecen simples piedras de aspecto nada atractivo, sin embargo, cuando se abren muestran su precioso contenido. Se forman al cristalizar sustancias disueltas o gases en cavidades de las rocas. Tablas II y III; Lámina II, figura 3.

Hay una anécdota muy curiosa relatada por García-RuIz (20I5) que tiene una geoda como protagonista:

"Cuentan que el profeta Elías, aquel que subió al cielo en carro de fuego, estaba penando en el desierto próximo al Monte Carmelo cuando fue partícipe de un hecho maravilloso. Llevaba días de ayuno y penitencia bajo el sol abrasador del Sinaí. Cuando las fuerzas ya flaqueaban, el hambriento y sediento anacoreta, a quien tanto se invoca en tiempos de sequía, fue tentado de la forma más terrible que uno pueda imaginarse. El demonio puso a su alcance medio melón abierto, jugoso y fresquito. Pero cuando el

16. Cuando es de este tamaño se denomina criptocristalino.

17. Debe su nombre a que es muy abundante en el condado de Herkimer (Nueva York) 
profeta y santo, ya babeaba ante el manjar del diablo, se dio cuenta de las verdaderas intenciones de la ofrenda, miró con los ojos desencajados al melón y dijo:"Atrás Satanás, conviértete en piedra".Y el melón se convirtió en una piedra.

En la iglesia del monasterio de las carmelitas descalzas en Sanlúcar la Mayor (Sevilla) hay una capilla dedicada a San Elías, y en ella, resguardado en una urna de cristal, el melón petrificado, orlado con el texto:"Melón convertido milagrosamente en piedra por San Elías". En realidad se trata de una geoda de calcedonia que cortada por la mitad, muestra cierto parecido con un melón, con un gradiente de textura desde el exterior más liso hasta el interior del hueco corazón, tapizado de cristales de cuarzo cristalino.

Respecto a sus propiedades terapéuticas se creía que podía curar las enfermedades del pecho si se utilizaba para comer en ella. Literalmente dice:"el que usa de comer en esta piedra [...] será seguro de no haber enfermedad en los pechos”.

\section{Capricornio}

Del 22 de diciembre al 20 de enero. Este signo, el décimo del Zodiaco, se simboliza por una cabra con cola de pez. Según una de las versiones representa a Amaltea, la nodriza que amamantó a Zeus cuando este era pequeño. La diosa Rea, su madre, quiso preservar a Zeus de la voracidad de su marido Cronos que devoraba a sus hijos conforme nacían, por lo que lo escondió en una cueva, en la isla de Creta, donde Amaltea cuidó de él hasta que fue adulto.

Del XXIII grado del signo de Capricornio es la piedra a la que dicen en caldeo melizlumen, que se ha interpretado como cantos rodados de cuarzo ${ }^{18}$ ya que se halla en la ribera del mar, a merced de las olas, en trocicos y granos como de arena, " $y$ cuando la quebrantan, hallan dentro en ella sustancia de vidrio".

Los cantos rodados son piedras pequeñas, lisas, sin aristas, más o menos redondeadas, subredondeadas u oblongas, que se han formado como consecuencia del desgaste sufrido en una corriente de agua. Pueden ser de cualquier naturaleza, minerales o rocas. Los de cuarzo pueden llegar a tener muy buen pulido y tacto muy frío (ésta es una característica distintiva de este mineral). Otra característica es su gran dureza. El cuarzo raya al vidrio y no puede ser rayado por la navaja. Los de pequeño tamaño se pueden usar directamente en joyería, como cuentas de collares, pulseras o colgantes. Tablas II y III; Lámina II, figura 4.

Hay un tipo de cantos rodados, exclusivos de la Comunidad de Madrid, que se denominan diamantes de San Isidro ${ }^{19}$. Estos pueden ser cristales de roca (o ahumados) que se forman en la sierra de Madrid y son transportados por el agua de ríos y torrentes, redondeándose y esmerilándose superficialmente (no llegan a pulirse bien), hasta que se depositan en las terrazas del Manzanares.

$Y$ de su virtud dice que puede quebrantar las piedras que se hacen en los riñones o en la vejiga, y que las hace echar en forma de arena menuda.

\section{Acuario}

Del 21 de enero al 18 de febrero. Acuario, Aquarius o el Aguador es el undécimo signo zodiacal. Se representa con un hombre que vierte el agua de una tinaja. Para algunos mitógrafos simboliza a Ganimedes "el más hermoso de los mortales". Cuando Zeus lo vio, se enamoró de él instantáneamente y lo llevó al Olimpo, donde lo hizo su amante y también copero divino, encargado de servir a los dioses.

La piedra seleccionada es el cahadenyz que corresponde al grado décimo del signo. Ha sido interpretada como fluorita, por su color violeta y porque la describe como mineral, refiriéndose posiblemente a que está cristalizada. Además dice que cuando la queman se hace liviana y porosa. Estas propiedades son muy características de la fluorita, que aunque puede presentar una gran variedad de colores, el violeta es uno de los más frecuentes, suele formar buenos y grandes cristales, cúbicos u octaédricos ${ }^{20} y$

18. También podría tratarse de cuarcita que es una roca metamórfica compuesta por hasta un 90-99\% de cuarzo.

19. Donde más abundaban era en la Pradera de San Isidro (hoy totalmente antropizada). En la actualidad los hacen artificialmente, redondeando cristales de roca (ahumados, rosas...) y luego abriendo una "ventana" (cortando y puliendo la superficie de corte) para ver el interior transparente.

20. La fluorita tiene exfoliación octaédrica perfecta, es decir, tiende a separarse en láminas que irían truncando los vértices del cubo dando lugar a octaedros de exfoliación. Aunque existen octaedros naturales, los más abundantes en el mercado son los de exfoliación tallados 
decrepita y se descompone al acercarla a una llama. Además tiene tacto vítreo y frío y densidad y dureza media (se raya con la navaja). Tablas II y III; Lámina II, figura 5.

En cuanto a sus poderes curativos dice que si la mezclan con las medicinas que hacen para el dolor del estómago lo mejora mucho. Y si pulverizada la aplican en los ojos claros, estos mejoran su visión nocturna y se curan si están enfermos.

\section{Piscis}

Del 19 de febrero al 20 de marzo. Piscis, Pisces o los Peces es la doceava y última constelación zodiacal, y representa quizás, a los dos peces en que se transformaron Afrodita y su hijo Eros para huir del gigante Tifón que amenazaba con matarlos. Se simboliza por dos peces ligados por un hilo.

Aunque este es el tercero de los signos incompletos de El Lapidario, en el que solo se han conservado dos descripciones de piedras, una de ellas denominada rezcuiden, correspondiente al grado veintinueve, ha podido ser seleccionada para este trabajo. Sus propiedades de fuerte, dura, pesada y lucia (refiriéndose posiblemente a su brillo vítreo - perlado) han permitido identificarla como baritina. Este es un mineral fácilmente reconocible al tacto, no solo por su alta densidad (pesa mucho en relación a su volumen) sino porque cristaliza en forma de placas, a menudo gruesas y de contornos redondeados, que a veces se disponen agrupadas formando una especie de flores denominadas rosas del desierto. Es frecuente que estos agregados tengan un tacto muy áspero debido a la inclusión de granos de arena. Tablas II y III; Lámina II, figura 6.

De sus poderes mágicos y curativos dice que los que ven al hombre que la lleva le aman, le temen y hablan bien de él.Además, molida y bebida quita el mal sabor de boca.

\section{ACTIVIDADES PROPUESTAS}

A partir de esta idea, se propone realizar talleres donde los participantes, una vez informados de las propiedades características de la piedra correspondiente a su signo, reconozcan esta mediante escrutinio táctil exclusivamente. Los grupos pueden estar integrados por personas ciegas o con deficiencia visual, por personas con visión intacta, o bien ser un grupo mixto. En estos últimos casos habrá que idear algún procedimiento que asegure el reconocimiento a ciegas de las personas que ven.

A cada uno de los participantes se le indicarán las cualidades que debe identificar, ya sea directamente por parte de los monitores encargados del taller o a través de una grabación. Para ello, puede resultar muy útil preparar unas fichas en las que figuren, de manera resumida, esas propiedades táctiles necesarias para encontrar la piedra correspondiente y también las otras propiedades mágicas y curativas que les reconoce El Lapidario y que constituyen la parte más divertida y exitosa del taller (aparte de la satisfacción que supone encontrar la piedra buscada). Asimismo, se recomienda no olvidar el comentario específico que se hace acerca del origen, utilidad o donde aparece cada una de las piedras descritas. Por ejemplo, no es igual buscar solo una piedra muy densa con tacto metálico y que es atraída por los imanes, que si además se sabe que tiene un origen extraterrestre y que en el siglo XIII se creía que sus limaduras y polvo, convenientemente tratadas podían curar casi todo, como es el caso del hierro para los nacidos bajo el signo de Tauro. Una vez conocidas estas características realizarán la exploración táctil de las diferentes piedras de la colección hasta reconocer la suya.

Hasta este momento se han realizado tres talleres en los que se ha mostrado la selección de piedras a diferentes grupos. En el primer taller participaron cuatro personas invidentes. El segundo taller se hizo en el transcurso de una visita al Museo de la Geología de la UCM por parte de dos grupos, integrados por quince adultos y quince adolescentes, que se prestaron voluntarios a hacer el reconocimiento táctil. El tercer taller se ofreció como actividad reglada a los visitantes de una conocida feria de minerales de Madrid. En este caso participaron 45 personas de todas las edades (mínimo 7 años); todas ellas con visión intacta. En estos dos últimos talleres las piedras se introdujeron todas juntas dentro de una bolsa opaca con solo dos aberturas para meter las manos y así hacer el reconocimiento a ciegas.

El éxito en el reconocimiento fue del $100 \%$ y el grado de satisfacción también fue notablemente alto. En el caso de las personas ciegas, o con discapacidad visual, la actividad les proporciona una experiencia que habitualmente solo pueden conocer de manera indirecta. Las piedras del Zodiaco suelen ser productos muy comerciales, pie-

artificialmente. 
dras coloreadas, más o menos transparentes, con formas redondeadas y muy pulidas, difícilmente reconocibles al tacto. Por otro lado, la leyenda que se asocia con cada signo y cada piedra les presta un interés especial que va más allá del mero reconocimiento de las especies minerales. En relación a las personas con visión intacta, la actividad supone una experiencia nueva, descubrir el valor de otros sentidos diferentes de la vista, esforzarse en su uso y comprobar cómo, en este caso, también les conduce al reconocimiento de minerales. Por último, tanto en uno como en otro colectivo, esta colección de piedras del Zodiaco representa una nueva simbología, con un alto potencial lúdico y cultural.

\section{CONCLUSIONES}

En El Lapidario de Alfonso $X$ el Sabio (libros primero y segundo) se identifican 209 tipos diferentes de minerales, rocas, fósiles, plantas y esqueletos o caparazones de animales que se distribuyen entre los doce signos del zodiaco. A partir de esta considerable muestra se han seleccionado doce piedras que corresponden a cada uno de los signos del Zodiaco y que son susceptibles de reconocimiento táctil. Esta colección:

Constituye un nuevo instrumento de percepción háptica que permite ampliar los recursos de personas con ceguera o discapacidad visual;

Contribuye a mejorar su conocimiento del mundo mineral (identificación, usos, variedades, etc.);

Les pone en contacto directo con temas de gran significado cultural y lúdico, como son la astrología y las piedras del Zodiaco, que habitualmente están vedados para ellos.

Para el colectivo de personas con visión intacta, la actividad supone un reencuentro con sus otros sentidos, diferentes de la vista, que también les permite el reconocimiento de los minerales involucrados.

Una condición para que estos ejemplares puedan ser reconocidos por el canal háptico, es que sus propiedades, susceptibles de escrutinio táctil, no sean comunes entre los diferentes miembros de una misma colección. Atendiendo a esta condición, se podrían elegir, entre los 209 ejemplares identificados, otras colecciones distintas de la que se describe en este trabajo y aumentar con ello las posibilidades culturales y lúdicas de la actividad propuesta.

\section{BibLIOGRAFíA}

Alfonso X el Sabio (s. XIII). Manuscrito h.l.I 5 de la Real Biblioteca del Monasterio de San Lorenzo de El Escorial, I 19 folios. Edición facsímil, 1982. El primer lapidario de Alfonso X el Sabio. 2 vols. (Vol. I: Códice.Vol. Il: El códice y su texto. Introducción y transcripción M. Brey Mariño, comentarios científicos J. L. Amorós Portolés). Ed. EDILAN, Madrid.

Amorós. J. L. 196I. “El Lapidario de Alfonso X el Sabio”. Boletín de la Real Sociedad Española de Historia Natural. Sección Geológica, 59: I3I-I55.

CHICOTE,J.C.,LÓPEZ-ACEVEDO,V.\& GOÑI,J.20 I 5.El lenguaje háptico de las piedras.Integración.Edición digital, 65. <http://www.once.es/new/servicios-especializados-en-discapacidad-visual/publicaciones-sobre-discapacidad-visual/nueva-estructura-revista-integracion/copy_of_numeros-publicados/numero-65/el-lenguaje-haptico-de-las-piedras/?searchterm=Chicote> [Consulta: 16-08-2017].

García RuIz,J. M. 2008. El misterio de los cristales gigantes. EL PAís. Edición impresa (05-10-2008). <http://elpais.com/diario/2008/I0/05/eps/I223/880I4_8502I5.html> [Consulta: I6-08$2017]$.

- 2015. El melón de San Elías ¿Fueron los considerados fósiles más antiguos del planeta puras estructuras minerales con formas caprichosamente biológicas?. El País. <http://elpais. com/elpais/2015/05/07/ciencia//431017789 237800.html> [Consulta: I6-08-2017].

LaPIDARIO (s.f.) Lapidario. Alfonso X Rey de Castilla. Instituto de Química Física Rocasolano y Consejo Superior de Investigaciones Científicas. <http://www.xtal.iqfr.csic.es/Cristalografia/ archivos_0l/lapidario.pdf> [Consulta: 25-07-20I7].

Oyarzún MuÑoz, J. 20I5. El campo magnético terrestre, evidencias e interrogantes. Revista de Marina, CXXXI (I 32: 949), 54-57.

Rodríguez M. Montalvo, S. 198I. «Lapidario» (según el manuscrito escurialense H.I.I5). En: II.Libro de las piedras según las fases de los signos). Ed. Gredos, Madrid. <http://www.cervantesvirtual.com/obra-visor/lapidario--0/html/00 la37de-82b2-I I df-acc7-002 I85ce6064_7. html> [Consulta: 16-08-2017]. 
Lámina I.Todas las imágenes llevan una moneda de 0,05 € como escala gráfica. Fotos: Irene Díaz Hernández. Fig. I. Aries. Magnetita. Cristales octaédricos sobre roca, con un imán adherido a ellos. Tamaño de los cristales 4 a $8 \mathrm{~mm}$. Color gris metálico. Tamaño de la muestra $8 \times 5 \times 3,5 \mathrm{~cm}$. Fig. 2. Tauro. Hierro. De izquierda a derecha: cascabel (diámetro $=13 \mathrm{~mm}$ ), manojo de cinco llaves (longitud 23 a $57 \mathrm{~mm}$ ), algunas oxidadas, y dos meteoritos $(15 \times 15 \times 15 \mathrm{~mm})$ de forma irregular con imán adherido. Color gris metálico. Fig. 3. Géminis. Granate. Seis cristales (diámetro $=25$ a $15 \mathrm{~mm}$ ). Presentan formas esferoidales facetadas: cinco trapezoedros y un rombododecaedro. Color granate oscuro. Fig. 4. Cáncer. Yeso. Seis cristales de forma romboidal. Cuatro pequeños (largo 21 a $40 \mathrm{~mm})$, muy transparentes e incoloros, planos y alargados, y dos más grandes $(50 \times 21 \times 13 \mathrm{~mm}$ to $65 \times$ 37 x 18), translúcidos y con sus aristas biseladas, surcadas por estrías paralelas. Fig. 5. Leo. Rubí. Cuatro cristales, color vino burdeos. Tres de ellos tienen forma de prisma hexagonal alargado ( $14 \mathrm{a} \mathrm{II} \mathrm{x} \mathrm{I5} \mathrm{a} \mathrm{I0} \mathrm{mm)} \mathrm{y} \mathrm{el} \mathrm{cuarto}$ es plano, de contorno hexagonal (diámetro $=20 \mathrm{~mm}$ ). Fig. 6.Virgo. Ámbar. Cinco piezas. Cuatro pequeñas (29 a $35 \mathrm{~mm}$ ) transparentes, de color ámbar, pulidas y lisas con formas irregulares. Una pieza grande en bruto (60 a $35 \mathrm{~mm}$ ) con forma irregular, color marrón oscuro y opaca.

Fig 1.- ARIES. Magnetita

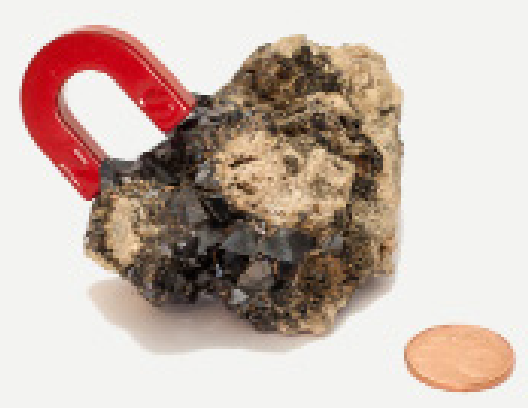

Fig 3.- GÉMINIS. Granate

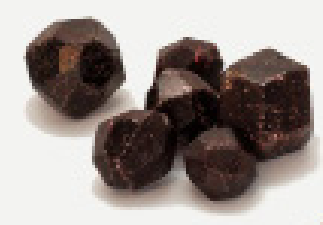

Fig 5.- LEO. Rubi

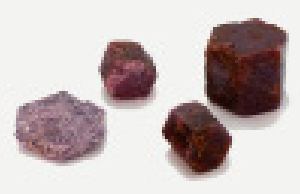

Fig 2.- TAURO. Hierro

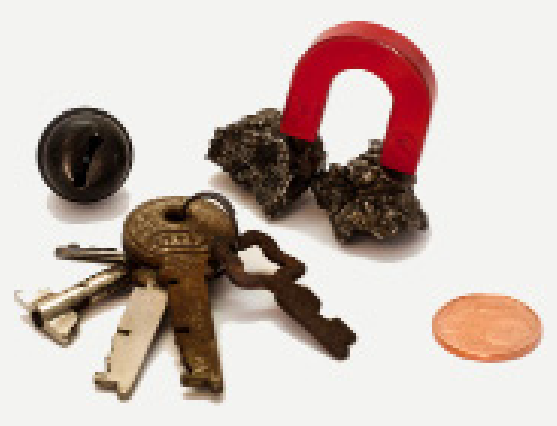

Fig 4.- CÁNCER. Yeso

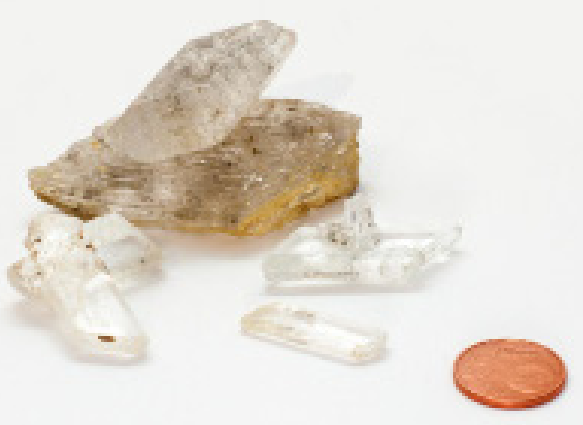

Fig 6.- VIRGO. Ámbar 
Lámina II. Todas las imágenes llevan una moneda de 0,05 € como escala gráfica. Fotos: Irene Díaz Hernández. Fig. I. Libra. Pirita. Cuatro cubos perfectos. Uno grande $(26 \mathrm{~mm})$ y tres pequeños $(15 \mathrm{~mm})$. Uno de estos muestra la superficie oxidada color marrón oscuro. El resto son dorados. Fig. 2. Escorpio. Cuarzo. Tres cristales, incoloros y muy transparentes. Forma de prisma hexagonal biterminado en bipirámide. Se trata de la variedad conocida como cuarzo Herkimer (45 x $19 \mathrm{~mm}$ ). Fig. 3. Sagitario. Geoda. Ejemplar de calcedonia, abierta en dos mitades. Color beige. Se observa su interior hueco, tapizado por cristales de cuarzo de color blanco. Diámetro $=60 \mathrm{~mm}$. Fig. 4. Capricornio. Cantos rodados de cuarzo. Cinco cantos rodados de color lechoso. Subedondeados, suaves y lisos. Cuatro grandes $(\approx 40 \mathrm{~mm}$ ) y uno pequeño $(\approx 19 \mathrm{~mm})$. Fig. 5.- Acuario. Fluorita. Dos octaedros de color verde (25 y $20 \mathrm{~mm}$ ). Fig. 6. Piscis. Baritina. Agregado de placas pseudoparalelas, gruesas y de perfil redondeado. Color blanco-gris. Tamaño aproximado de la muestra $65 \times 60 \times 45 \mathrm{~mm}$.

Fig 1.- LIBRA. Pirita

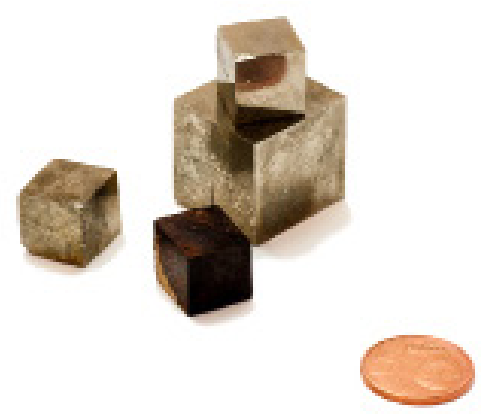

Fig 3.- SAGITARIO. Geoda

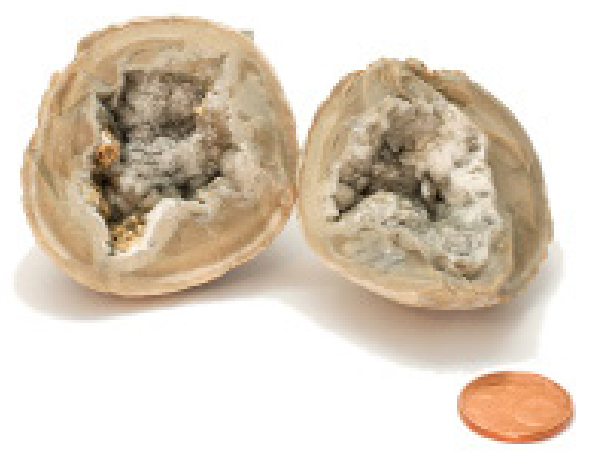

Fig 5.- ACUARIO. Fluorita

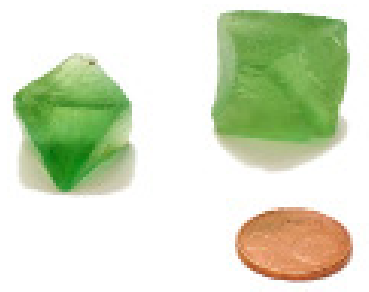

Fig 2.- ESCORPIO. Cuarzo

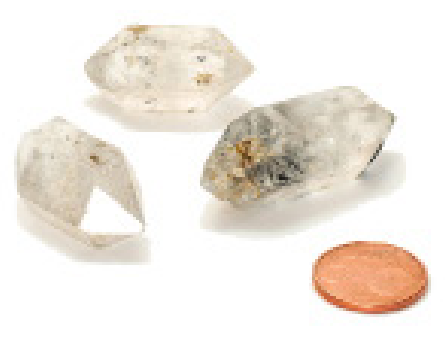

Fig 4.- CAPRICORNIO.

Cantos rodados de cuarzo

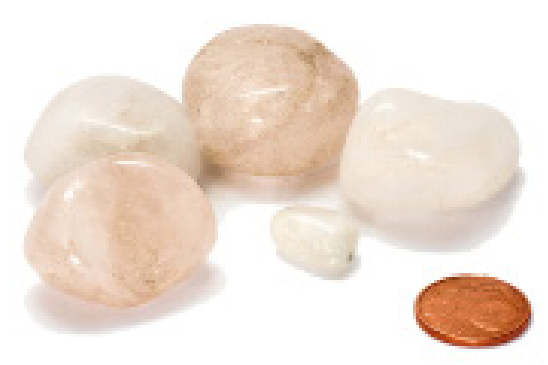

Fig 6. - PISCIS. Baritina

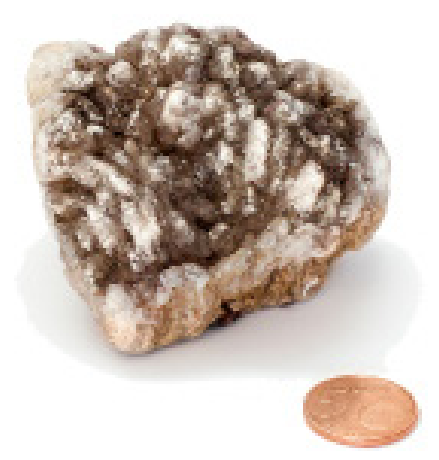


